\title{
Research Paper \\ Sustainable Rural Tourism in the Margins of Tehran Metropolis (From the Perspective of Ahar)
}

\author{
Mohammad Reza Rezavani ${ }^{1}$, Seyyd Ali Badri², Zabihullah Torabi ${ }^{3 *}$, Ahmad Malekan ${ }^{3}$
}

1. Full Professor, Department of Human Geography, Faculty of Geography, University of Tehran, Tehran, Iran

2. Associate Professor, Department of Human Geography, Faculty of Geography, University of Tehran, Tehran, Iran.

3. PhD Candidate, Department of Geography and Rural Planning, Faculty of Geography, University of Tehran, Tehran, Iran.

4. Associate Professor, Department of Disaster, Emergency, and Business Continuity Management, School of Administrative Studies, York University, Toronto, Canada.

ctitat on: Rezavani, M. R., Badri, S. A., Torabi, Z., \& Malekan, M. (2016). Sustainable Rural Tourism in the Margins of Tehran Metropolis (From the Perspective of Ahar). Journal of Rural Research, 7(2), 286-299.

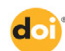

Received: 11 Dec 2015

Accepted: 14 May 2016

Key words:

Sustainable development, Tourism, Rural areas, Stakeholders analysis, Ahar

\section{A B STRACT}

Due to the failure of development programs, it is necessary to revisit the concept of sustainability. Sustainability is the frontispiece of all development actions and programs, such as the rural tourism. Therefore, the main factor in the progression of the development goals is to attain a common view about the issues. This qualitative study attempts to survey the sustainable tourism dimensions in villages located in the margin regions of Iran's metropolises (Ahar) by using perceptions and attitudes of stakeholders. The required data was collected using interviews with key stakeholder tourism groups (local executives, tourists, immigrants, and residents). The results showed that tourism does not have proper sustainability in economic, socio-cultural, and environmental pillars. Generally, there is no interrelation and balance among the three pillars of sustainable tourism. It seems that the lack of sustainability of tourism activities in Ahar is mainly due to structural weakness, lack of understanding of stakeholders of sustainable development, lack of requirement training, legal barriers, and failure to establish an optimal balance between the stakeholders' benefits.

\section{Extended Abstract}

\section{Introduction}

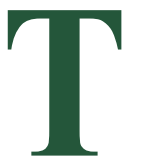

he development of tourism in rural areas has different positive and negative economic, socio-cultural, and environmental effects; hence, studying the development of sustainable tourism is necessary and inevitable in order to have a comprehensive understanding of the work. This paper attempts to use and analyze the perceptions and attitudes of key stakeholders in tourism with respect to three dimensions (economic, social, cultural and environmental) in the villages along the Tehran metropolises.

\section{Methodology}

In this qualitative method, information was collected through semi-structured interviews with 40 key stakeholder groups (migrants, residents, tourists and executives) who were selected using purposive snowbal sampling. The interviews started with three general

\section{* Corresponding Author:}

Zabihullah Torabi, PhD Candidate

Address: Department of Geography and Rural Planning, Faculty of Geography, University of Tehran, Tehran, Iran.

Tel: +98 (936) 5552675

E-mail: torabi.zabih@gmail.com 
questions on the impact of tourism on three aspects of sustainable development. The extracted information was analyzed and interpreted by highlighting the main points and ordering the documents (coding) and interviews (the interviews were tape recorded). To ensure the validity of the findings, we shared the findings with the stakeholders, and they reviewed the analyses.

\section{Results}

Socio-cultural effects: It seems that the purpose and type of tourism in rural areas have an impact on the stability of the region. Environmental impact: The participants believed that awareness as a means of achieving the goals is a voluntary orientation. If people have enough information on this subject without coercion, they will work in this direction.

Economic effects: The study showed that the residents and immigrants are more satisfied with improving their economic situation than in the past. However, they expressed that economic growth was not in line with economic stability, and it would not lead to controlled economic growth and local and fair distribution of economic benefits.

\section{Discussion}

Nowadays, the issue of sustainability is proceeding to all actions and developmental programs like rural tourism. Thus, scientists frequently have emphasized on triple values and goals of sustainable development which includes environmental, economic and socialcultural dimensions and clearly stated that sustainable development achievement without integration of these dimensions and their combination will be impossible. This study attempt to survey the sustainable tourism dimensions in villages located in the margin regions of Iran's metropolises using perceptions and attitudes of stakeholders.

The interviews with stakeholders show that rural tourism can create new job opportunities and contribute to the diversification of employment in rural areas; but if this approach is not in harmony with the principles of sustainability, it would be an adhoc approach. So it is necessary to comprehensively consider the effectiveness of the measures in the programs of economic development, environmental issues and socio-cultural values. The results show that although the growth of tourism in rural areas around the cities creates employment opportunities and diversification but it failed to coordinate with the criteria and objectives of sustainable develop- ment so that no relationship and balance was found between the three dimensions of economic, social cultural and environmental sustainability; even this growth has not been able to separately lead to relative stability.

\section{Conclusion}

Research findings show that most of the stakeholders do not have an understanding of sustainable development concepts and are not clearly familiar with its principles. On the other hand, local laws and management not only did not play a role in reducing the burden; they created management problems. Furthermore, there was no cooperation and coordination among stakeholders to resolve problem so that the incomplete spirit of individualism and the dominant thought of the development of economic growth and sustainable development were highly significant in the related groups. However, according to the opinions of the stakeholders, the development of sustainable tourism should provide an optimal balance among the interests of all concerned parties. Thus, structural weakness, lack of required training and legal obstacles exacerbate the problems.

Hence, reforming laws and undertaking development plans, improving education, and ultimately the coordination and balance among the interests of stakeholders in the tourism sustainability can help the unrestrained situation of rural of Tehran metropolis. Eventually the results show that tourism does not have proper sustainability in the all three economic, socio-cultural and environmental pillars. Generally, there is not any interrelation and balance among the three pillars of sustainable tourism. It seems that unsustainability of tourism activities in the margins of Iran's metropolises mainly is due to structural weakness, lack of understanding of stakeholders of sustainable development, Lack of requirement trainings, legal barriers and failure to establish an optimal balance among stakeholders' benefits. 


\title{
ارزيابى توسعه يايدار تَردشَّى در مناطق روستايى حاشيه كلانشهر تهران (مورد مطالعه: روستاى آهار)
}

\author{
محمدرضا رضوانى'، سيدعلى بدرى'؛ "ذبيحالله ترابى"، احمد ملكان"، على عسكرى" \\ 1. استاد تمام، كروه جغرافياى انسانى، دانشكده جغرافيا، دانشعاه تهران، تهران، ايران.

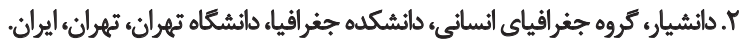

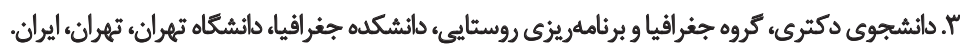

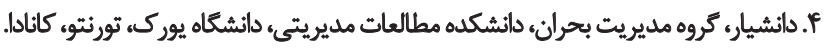

\begin{abstract}
حكיe

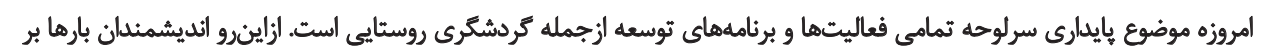

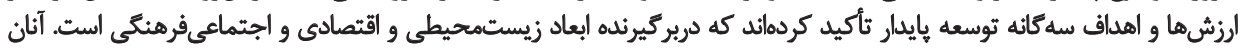

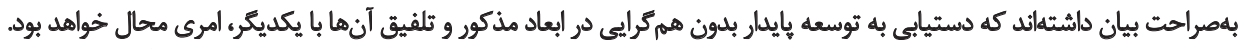

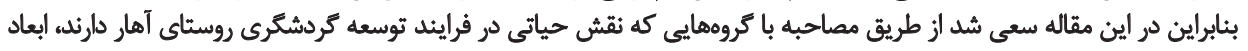

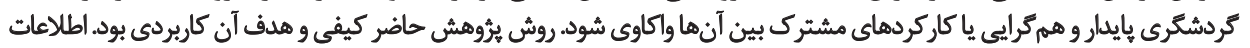

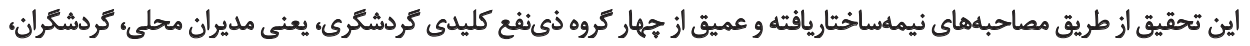

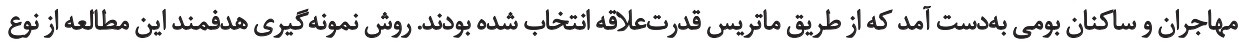

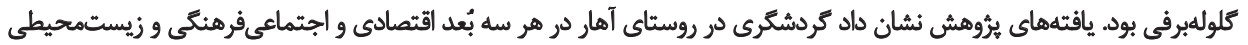

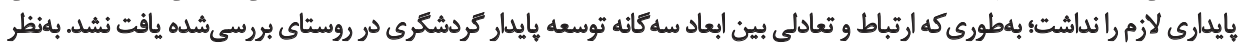

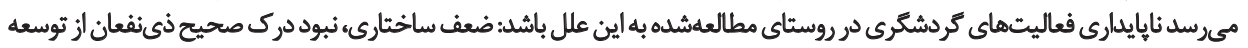

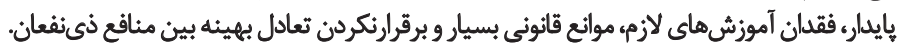

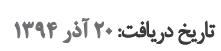

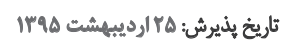

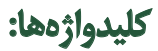
توسعه هايدار، كردشكرى، نواحى روستايي، تحليل ذينفعان، روستاي آهار
برايناساس بسيارى از جوامع دريافتهاند بايد نتكرشى واكنشى

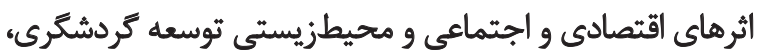

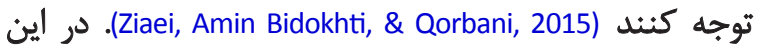

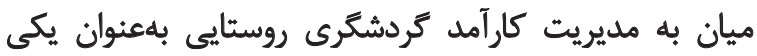

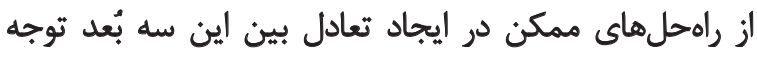

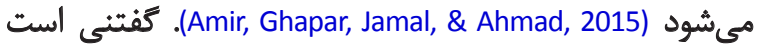

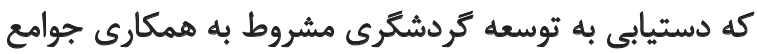

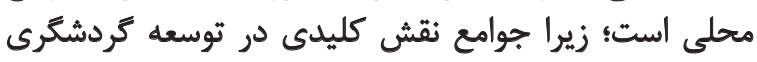

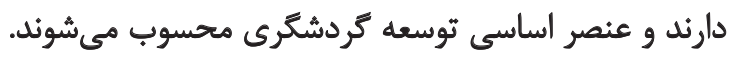

(Ziaei, Amin Bidokhti, \& Qorbani, 2015).

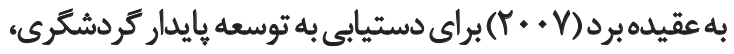

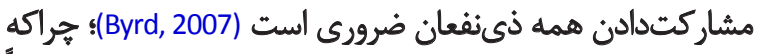

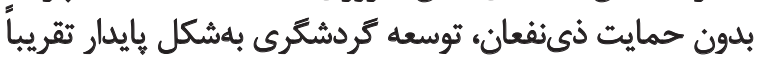

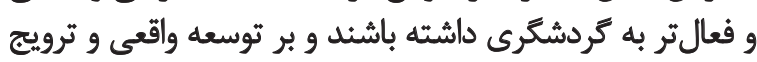

dost)

كردشگرى روستايى در دهاهاى اخير از رشد فزايندهاى

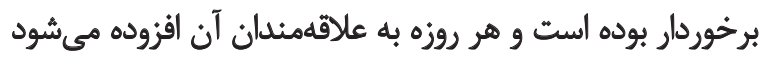
؛(Hall, Roberts, \& Mitchell, 2003; Kim \& Jamal, 2015; Snieška,)

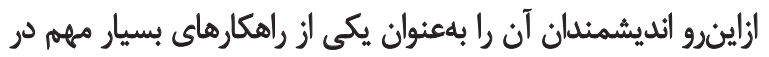

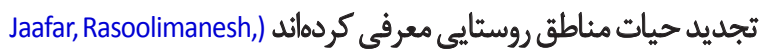

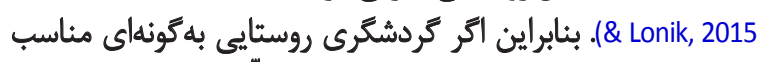

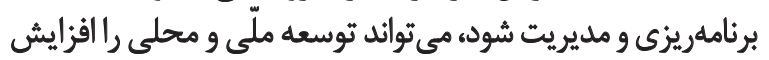

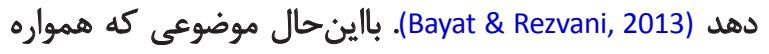

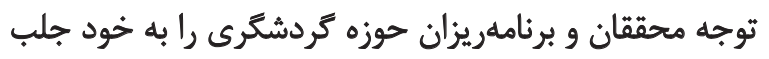

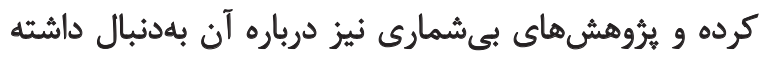

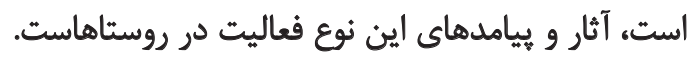
.(Byrd, Bosley, \& Dronberger, 2009)

$$
\text { ㄷ..…… }
$$

\section{"نويسئده مسئول:}

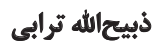

نشائى: تهران، دانشكاه تهران، دانشكده جغرافيا، كروه جغرافيا و برنامهريزى روستايى. + تلفن: torabi.zabih@gmail.com يست الكترونيكى 
به يك دوره نامحدود، بدون زوال يا تغيير محيطى و ارتقاى كرامت انسانى اشاره دارد (Butler, 1991; Fun, Chiun, Songan, \& Nair, 2014). فلسفه بايدارى در گزارش كميسيون برانتلند باعنوان لآينده

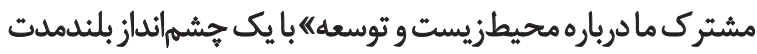
در بهرهبردارى از منابع در مجامع جهانى (Abbas \& Bajunid, 2015)،

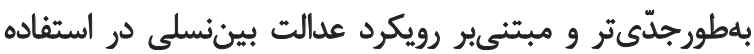

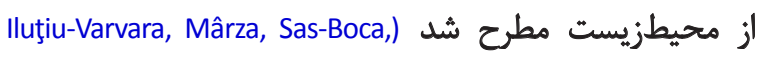

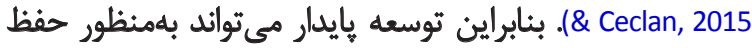

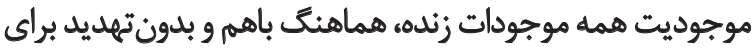

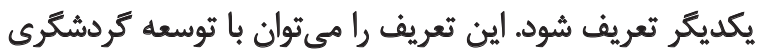

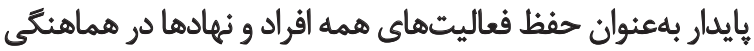

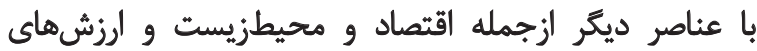
فرهنكىاجتماعى انطباق داد (Ekinci, 2014).

مفهوم هايدارى اجتماعىفرهنكى با معيارهايى مانئ رعايت

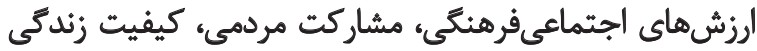

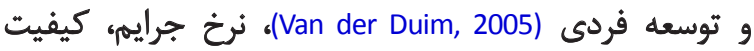

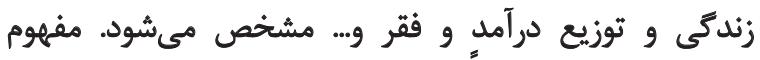

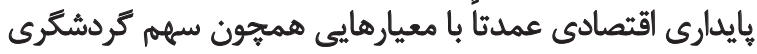

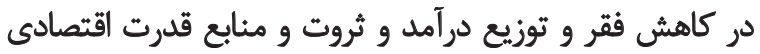

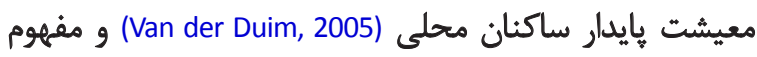

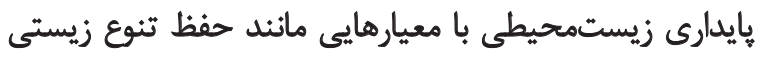

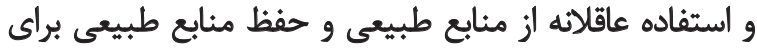

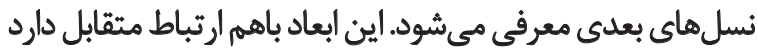

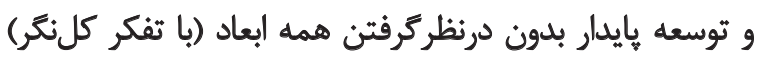
تحقق نخواهد يافت. بههرحال توسعه بايدار يرداختن به همه اجزا يا ابعاد بارويكردى

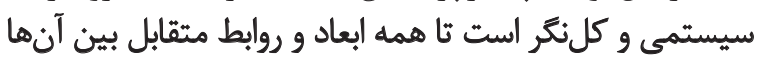

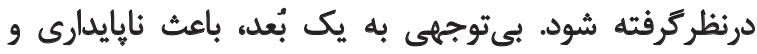

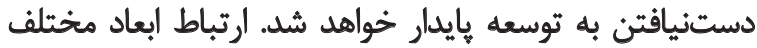
توسعه بايدار در تصوير شماره ا نشان داده شده است. سازمان جهانى كردشَّرى معتقد است دخالت ذئنفعان در اين

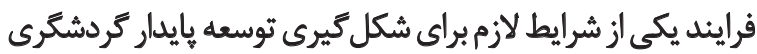

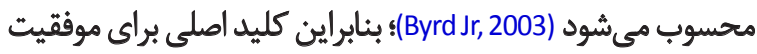

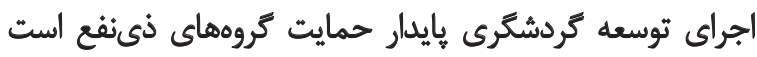

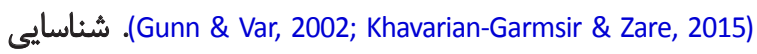

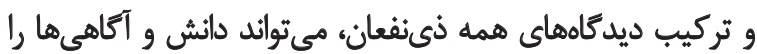

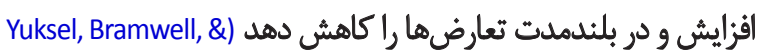
(Yuksel, 1999

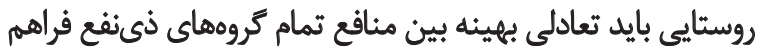

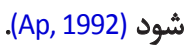

نظريه ذَىنفعان معتقد است برنامههاى كردشكُى ثاكنون

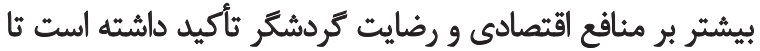

ناممكن است. بنابراين بررسى و شناخت كامل نكَرش ها و علايق

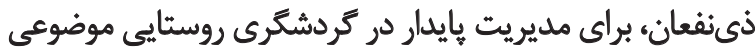
اجتنابنايذير محسوب مى مدود (Byrd, 2007).

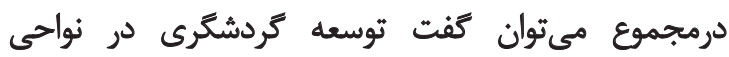

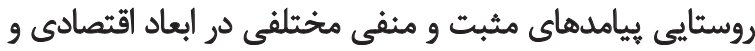

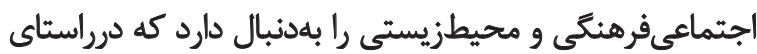

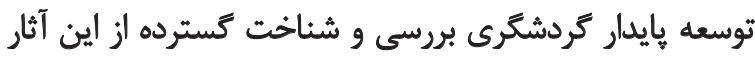

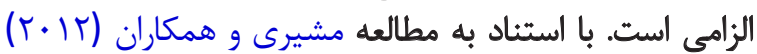

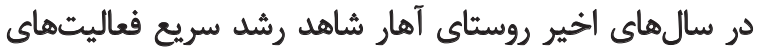

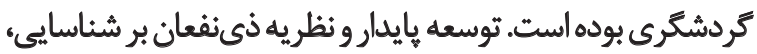

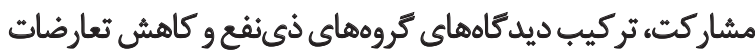

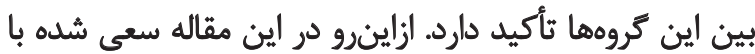

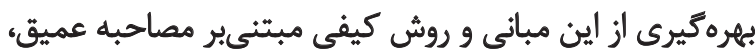

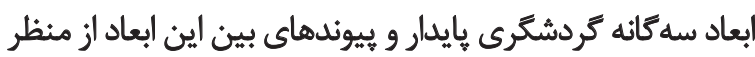

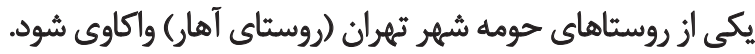

\section{r. مرورى بر ادبيات موضوع}

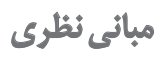

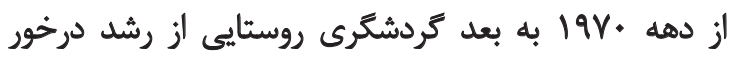

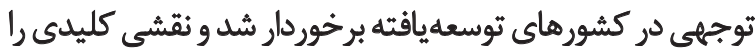

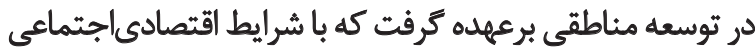
نامطلوب مواجه بود (Su, 2011; Yagüe Perales, 2002)؛ زيرايرا

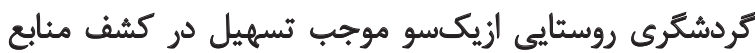

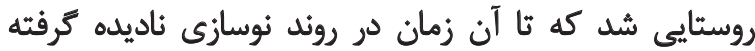

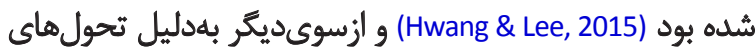

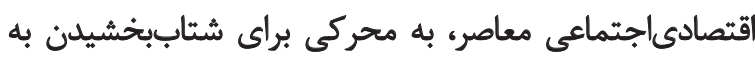

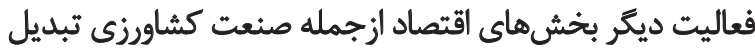

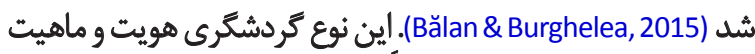

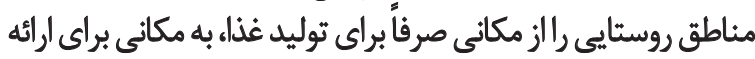
امكانات و تسهيلات روستايى تغيير داد (Hwang \& Lee, 2015).

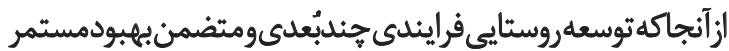

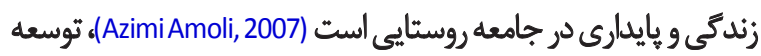

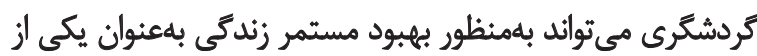

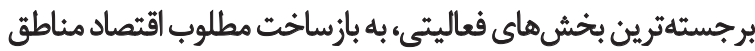

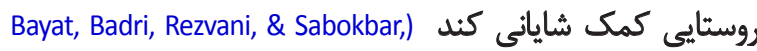

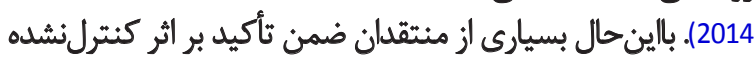

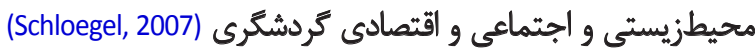

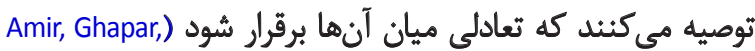

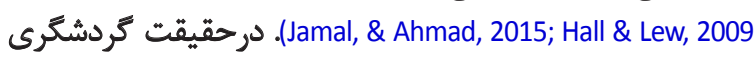
بايدار بلهنبال افزايش اثرهاى مثبت و كاهش اثرهاى منفى است (Khavarian-Garmsir \& Zare, 2015; Weaver, 2006) كردشكَّى مبتنى بر توسعه و خايدارى تأكيد دارد: توسعه هايدارى كه 


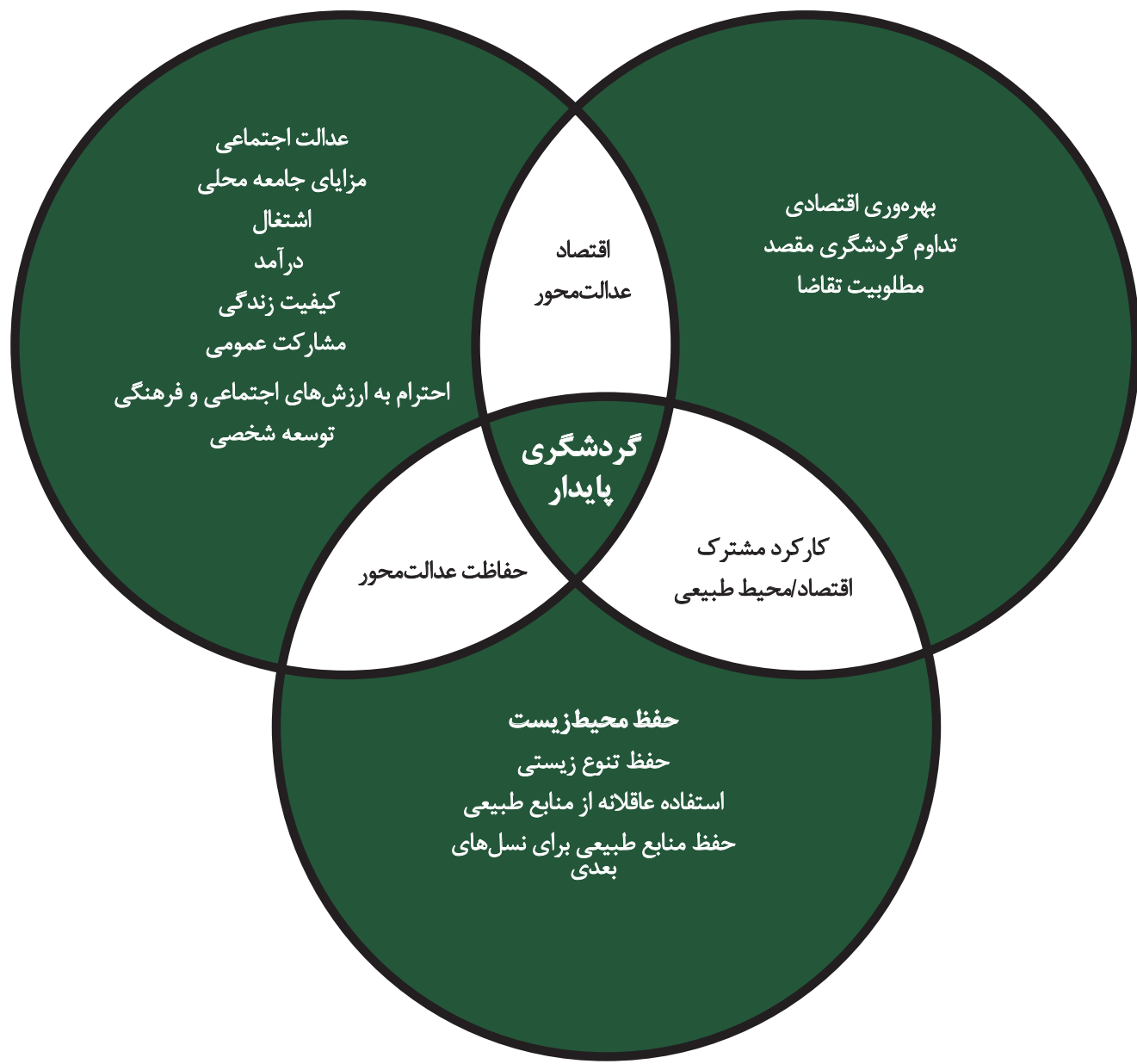

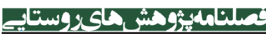

تصوير ا. ابعاد توسعه بايدار كردشكُى روستيايى (Fons, Fierro, \& Patiño, 2011; Khavarian-Garmsir \& Zare, 2015).

بايد درنظرداشت كه ديد كاههاى ذئفعان در توسعه گردشكرى

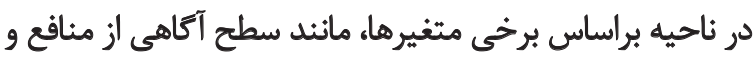

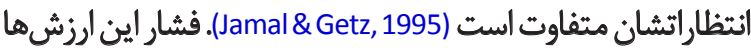

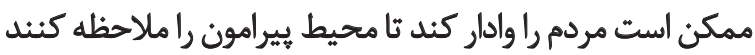

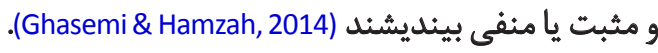

$$
\text { معرفي روسناى آهار }
$$

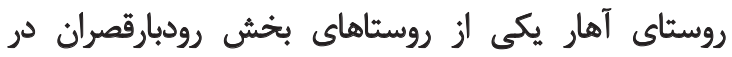

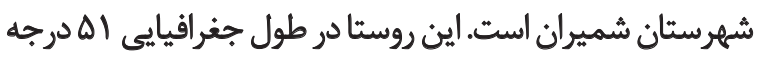

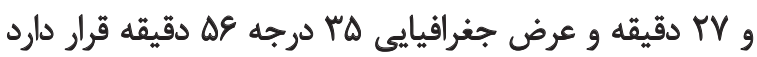

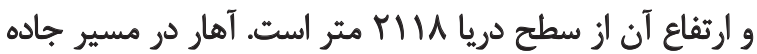

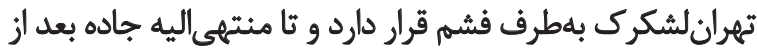

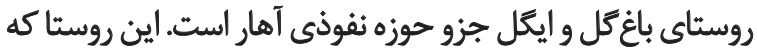

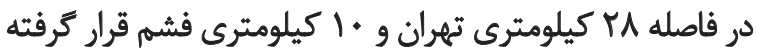

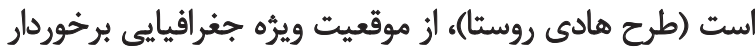

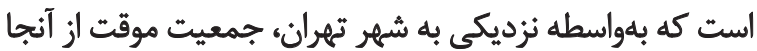
استقبال مي كنيند.
مشاركت ذى مثفعان؛ درصورتى كه مشاركت فعال آنها عاملى مهرم

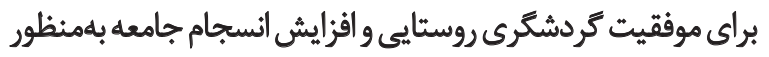

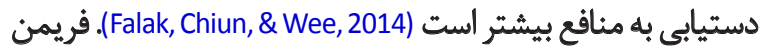

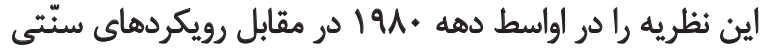

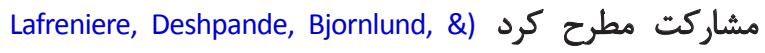

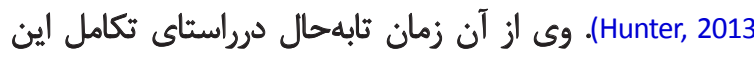

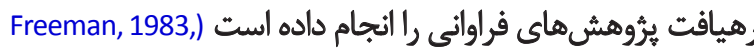
2004, 2010; Freeman, Harrison, \& Wicks, 2007; Freeman \& Phillips, 2002; Harrison \& Freeman, 1999; Phillips, Freeman, \& .(Wicks, 2003; Wicks, Gilbert Jr, \& Freeman, 1994

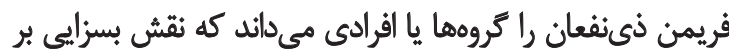

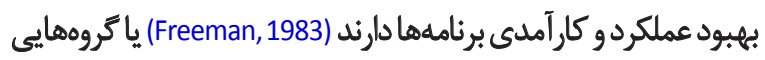
كه براي بقاي شركت حياتي هستيند (Friedman \& Miles, 2006) . به مانه

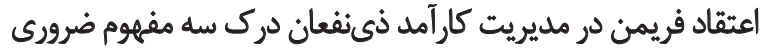

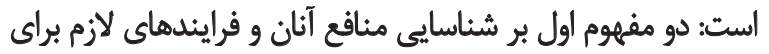

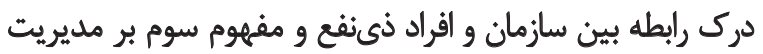

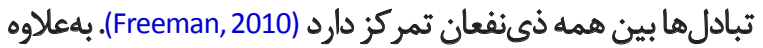




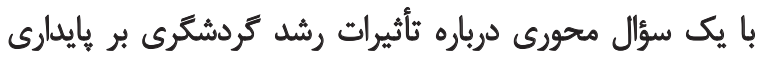

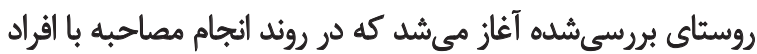
مختلف بنابر ضرورت تعديل يا تشريح مىشد. فرايند كردآورى اطلاعات تا سطح اشباع نظرى و وآستانه

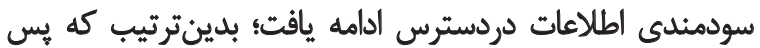

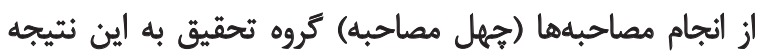

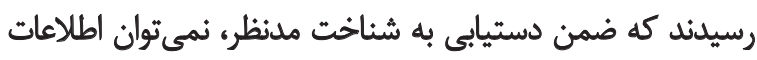

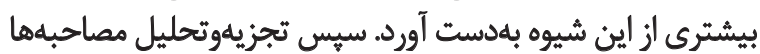

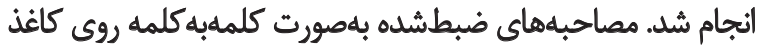

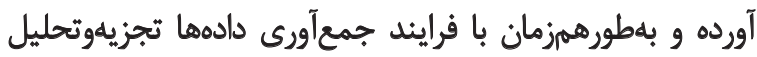

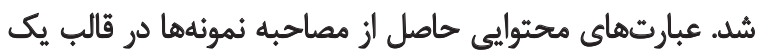

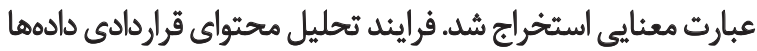

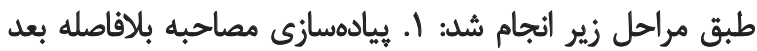

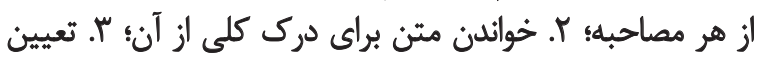

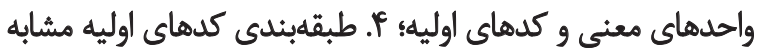

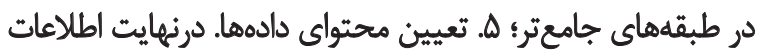

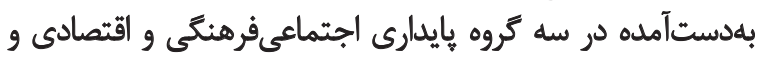
محيطزيستى دستهبندى شيد.

\section{انتخاب ذئنفعان}

براى شناسايى ذئفعان تأثيركذار و تأثيريذير، از ماتريس

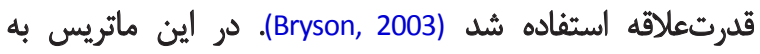

$$
\text { سؤالهايي از اين دست ياسخ داده شد: }
$$

1. جه كروههايى در داخل و خارج روستا از انجام فعاليتهاى

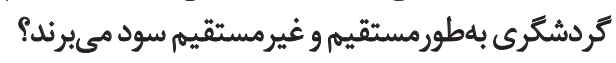

ك. كدام سازمانها و نهادها ممكن است قوانين و آيين نامههايشان

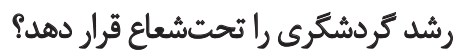

r. همكارى با كدام كروهها و نهادها كيفيث فعاليتها و نتايج

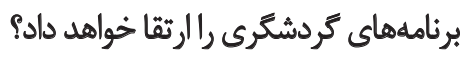

به اين ترتيب فهرستى از تمام كروههاي ذينفع داخلى وخارجى

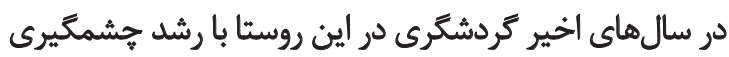

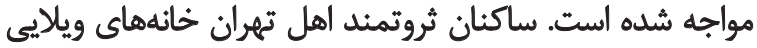

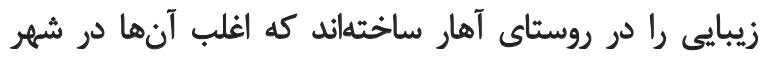

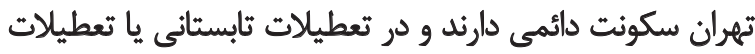

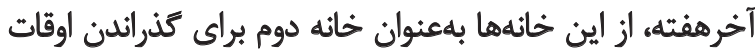

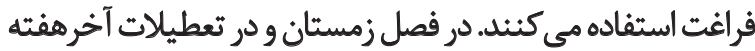

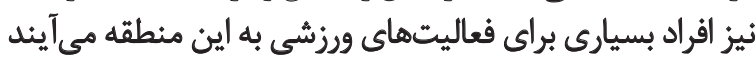

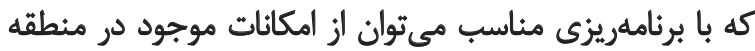

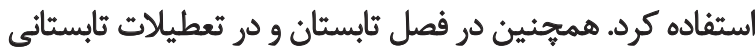

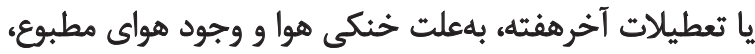

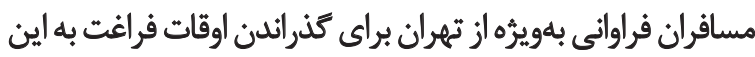
منطقة سيفر مي كنيند (Moshiri, Mahdavi, \& Jalali, 2012).

$$
\text { ب. ب. روش شناسى ثحقيث }
$$

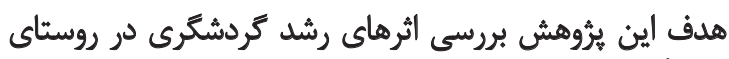

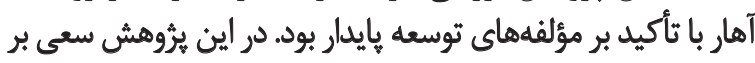

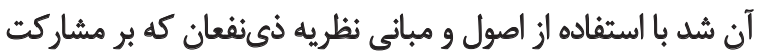

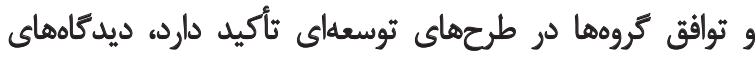

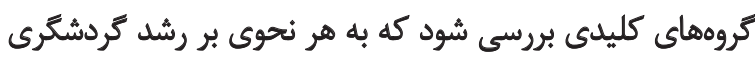

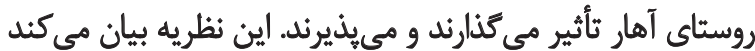

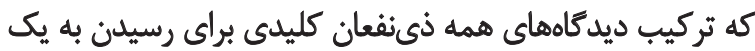

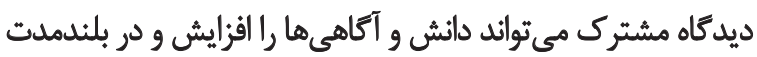

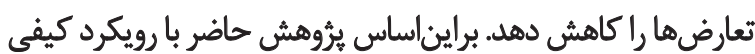

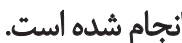

اطلاعات اين مطالعه از طريق مصاحبه نيمهساختاريافته از جهار

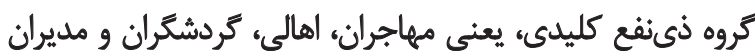

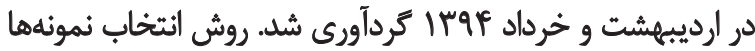

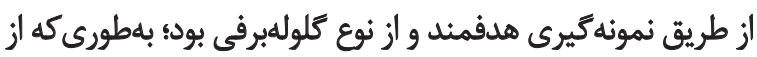

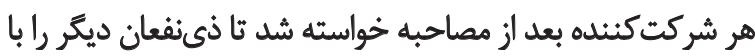

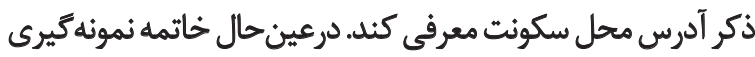

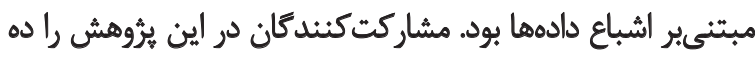

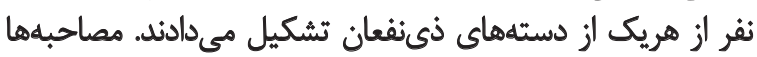

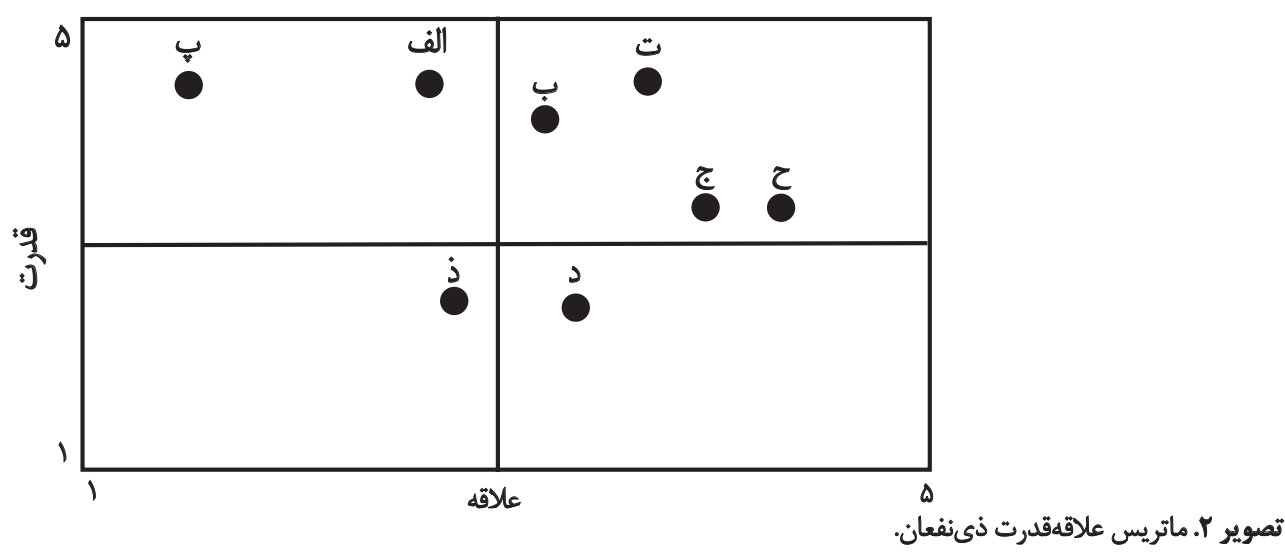


رستورانهاى فراوان در اين منطقه مي تواند درآمد فراوانى براي

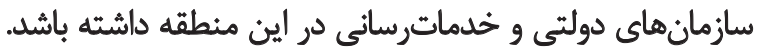

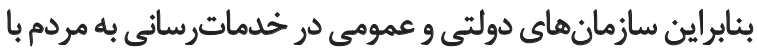
دستباز عمل مى كنينده (يكى از مديران). يافتههاى يرُوهش در زمينه مشاركت فعالانه مردم بر نداشتن

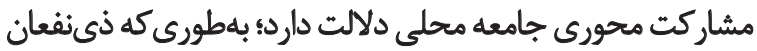

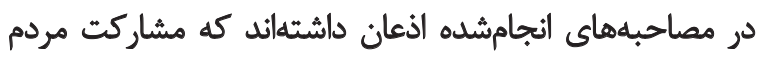

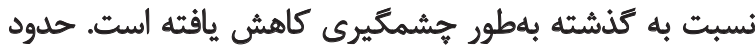

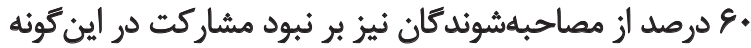

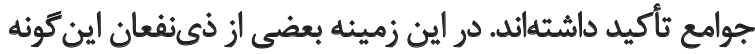

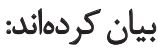

دازيكسرف با ورود افراد جديد در روستا در قالب خانههاى

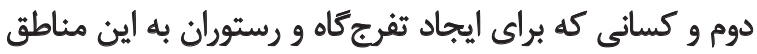

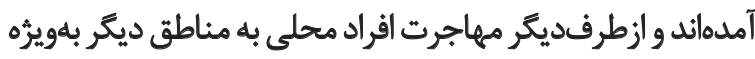

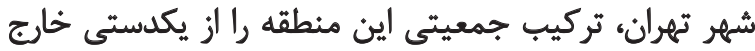

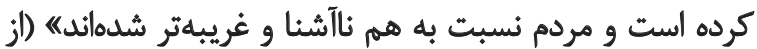

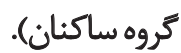

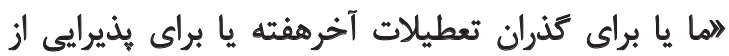

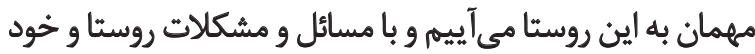

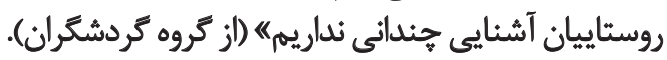

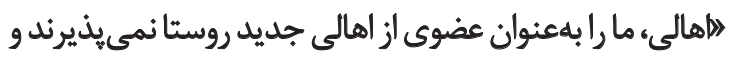

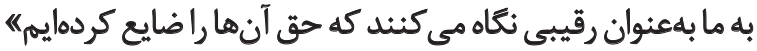

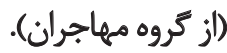

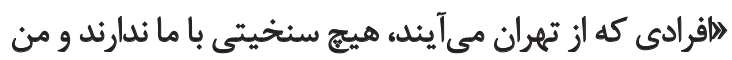

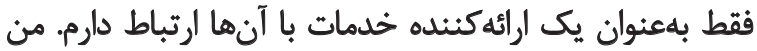

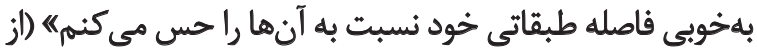
كروه مهاجران).

محتواى مصاحبههاي انجامشده مشخص مئكند بان با ورود

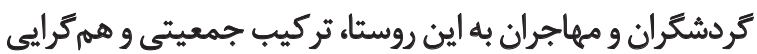

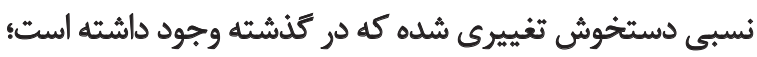

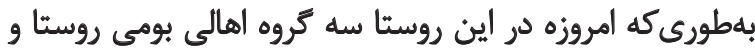

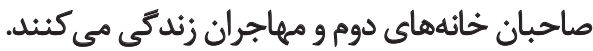

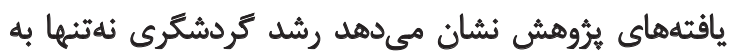

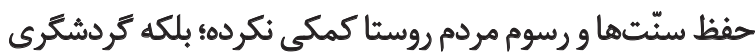

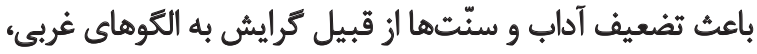

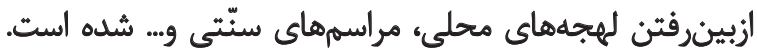

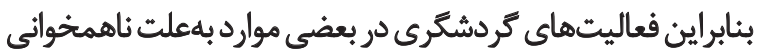

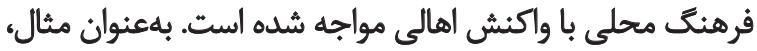

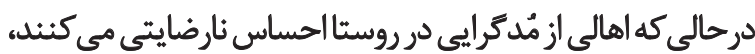

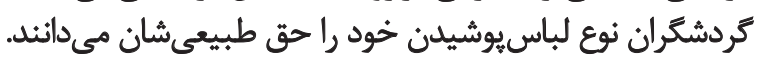
بهنوان مثال، يكي از مهاجران اذعان داشت:

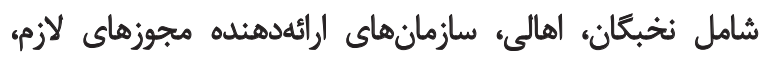

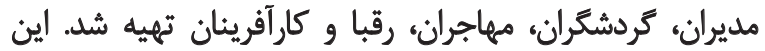

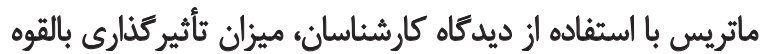

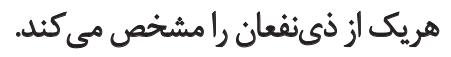
براساس ماتريس قدرتعلاقه (تصوير شماره Y)، ذئنفعان كروه

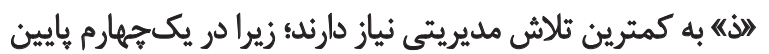

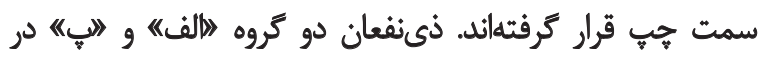

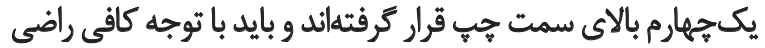

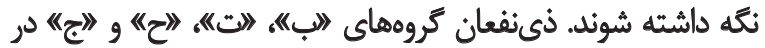

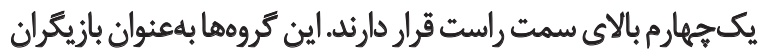

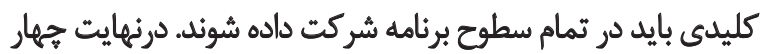

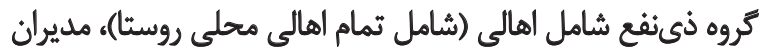

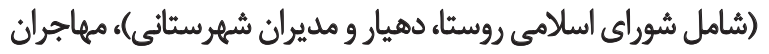

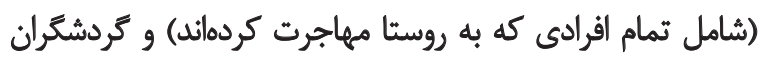

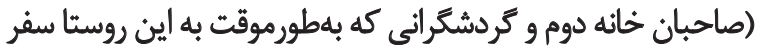
مى كنثد) مشخص و براي انجام مصاحبه دها انتخاب شداند.

أf

\section{اثر اجتماعىفرهنئي}

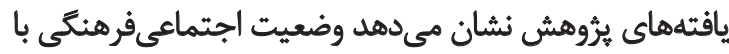

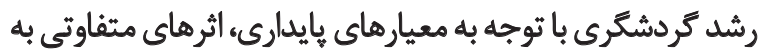

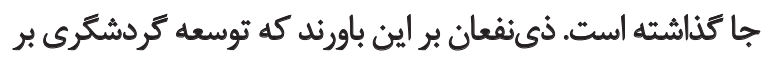

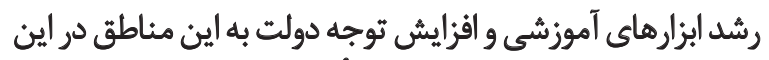

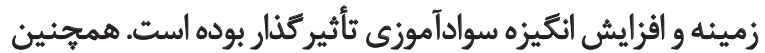

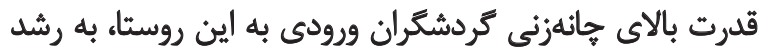

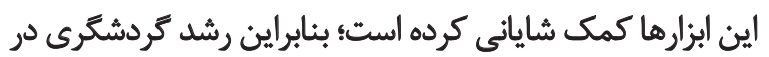

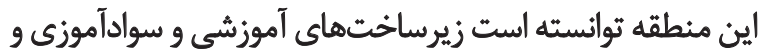

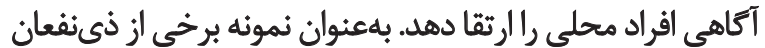

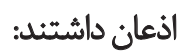

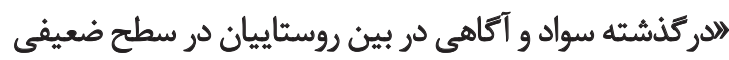

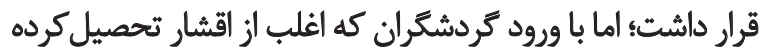

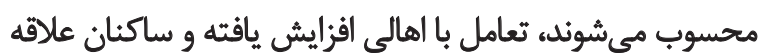

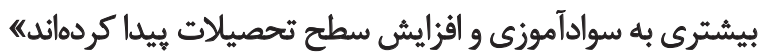

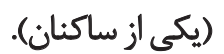

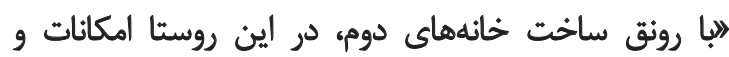

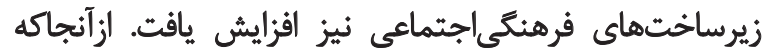

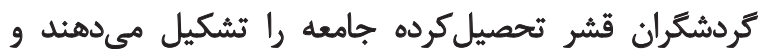

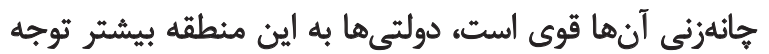

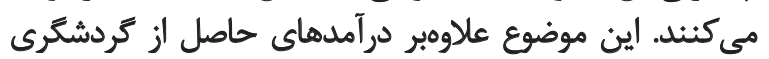
استه (يكى از ميهاجران).

الاساخت خانههاى دوم، خريدوفروش زمين و وجود 
طبقاني جامعه را تحملنكردنى توصيف كردماند. ساكنان محلى

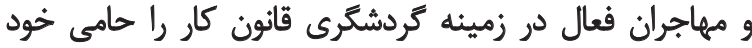

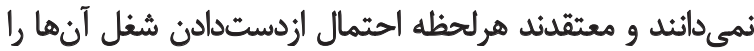
تهديد مى كند. بهعنوان مثال ساكنان و مهاجران دراينباره مئك كويند: المن خائه و زمينهاى خود راده سال بيش بلهعلت رشد قيمت

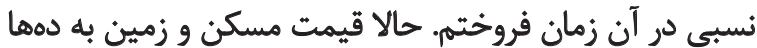

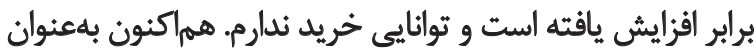
نتَّبان خانههاى ويلايى مشغول به كار شدهام (از كروه ساكنان). البا وجود افزايش درآهد و اشتغال براي جوانان روستا، اين

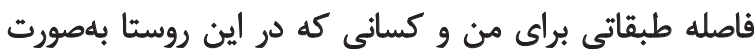
دائمى زندگى مى كنيم، تحمل كردنى نيست كنى (از كروه ساكنان). الصاحب رستورانها يا هتل ها از بيمهكردن ما سربازمىزنئد و

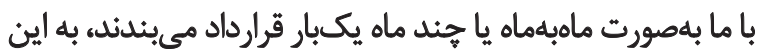
دليل از آينده خود مي ترسمه (از كروه مهاجران ماني). البهعلت نبود قوانين مالياتى محكمم و مدوّن، بيشترين دليل

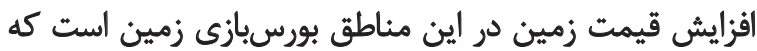

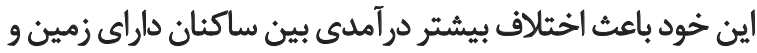
روستاييان فاقد زمين مي خودها (از كروه مديران).

اثر محيطز يسيتي

تحليل مصاحبهها نشان مىدهد با ورود كردشكران و ريختن

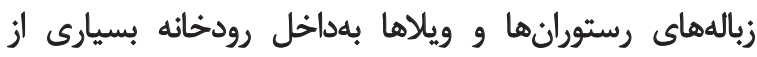

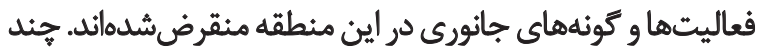

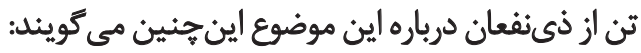
القبل از انقلاب كردشكُى در اين منطقه رونقى نداشت و در

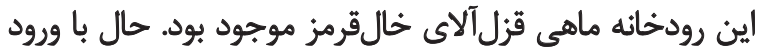

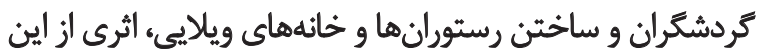
نوع ماهى خاص يافت نمىشوده (از كروه ساكنان). البا رونق كردشكَرى ديكر فعاليت كشاورزى و باغدارى

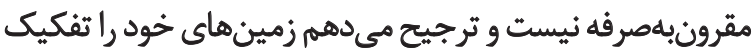
كنم و براى ساختوساز بفروشمه (از كروه ساكنان). همجنين ذينفعان درباره ساختوسازها اذعان داشتهاند كه

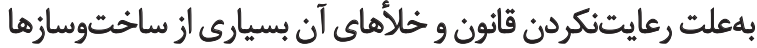

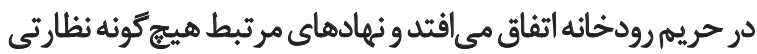

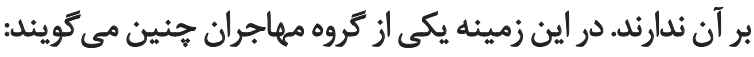
حاصلاً بر ساختوسازها در حريم رودخانه نظارتى نمى برشودي؛

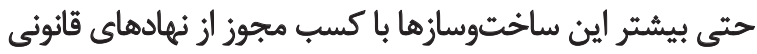

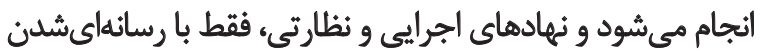

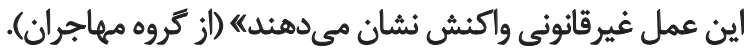
بسيارى از ذىنفعان افزايش تردد وسايل نقليه، آلودكى صوتى،

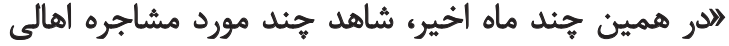

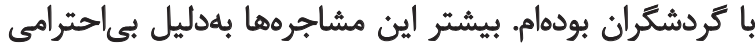

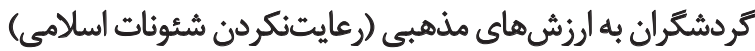
رخ داده استه (از كروه مهاجران). ازطرفديكّر يكى از كردشكران معتقد است:

الما براي اين ويلا ميلياردها تومان هزينه كردهايم كه فقط

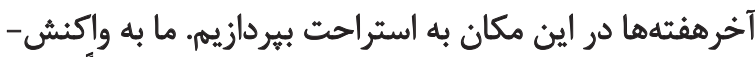

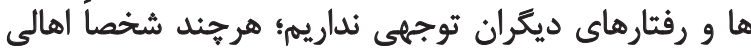

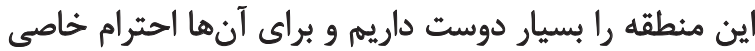
قائليمه (از تروه كردشكران).

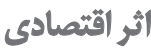

يافتهاى يُروهش نشان مي دهد رشد كردشكرى اثر اقتصادى

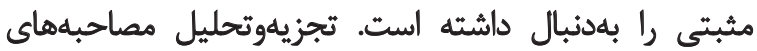

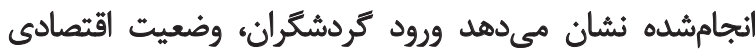
ساكنان و مهاجران و مديريت محلى را ارتقا داده است.

در اين روستا اشتغال از كشاورزى و باغدارى بهسمت مشاغل

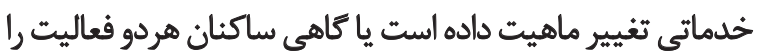

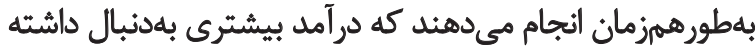

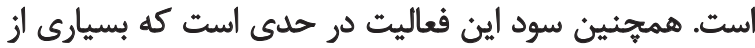

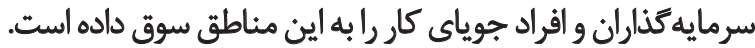

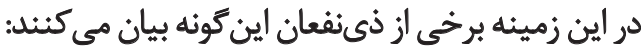

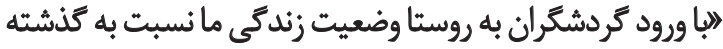
بهتر شده است و من از اين وضعيث راضى هستم به (از كروه ساكنان). البيشترين درآمد مديريت محلى از طريق صدور يروانههاي إندائ

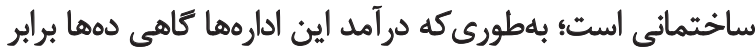
نسبت به قبل افزايش يافته استه (از كروه مديران).

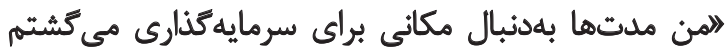

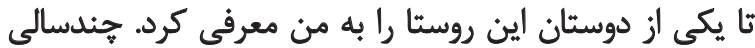

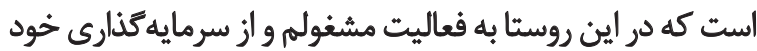

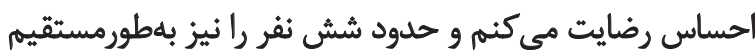
مشغول بهكار كردهام) (از تروه مهاجران).

براساس اظهارات و تحليل مصاحبهها اين افزايش درآمد بإيدار

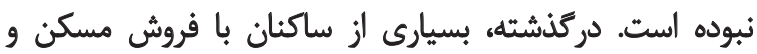

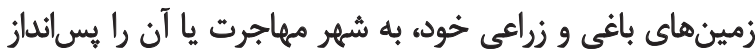

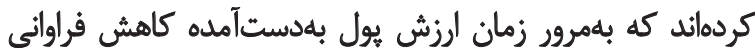

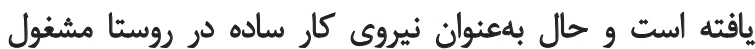

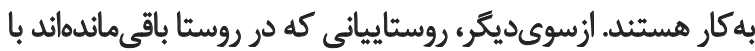

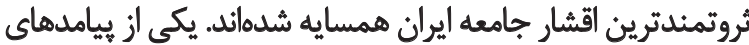

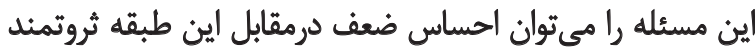

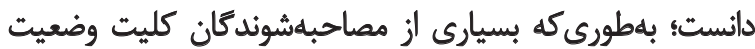




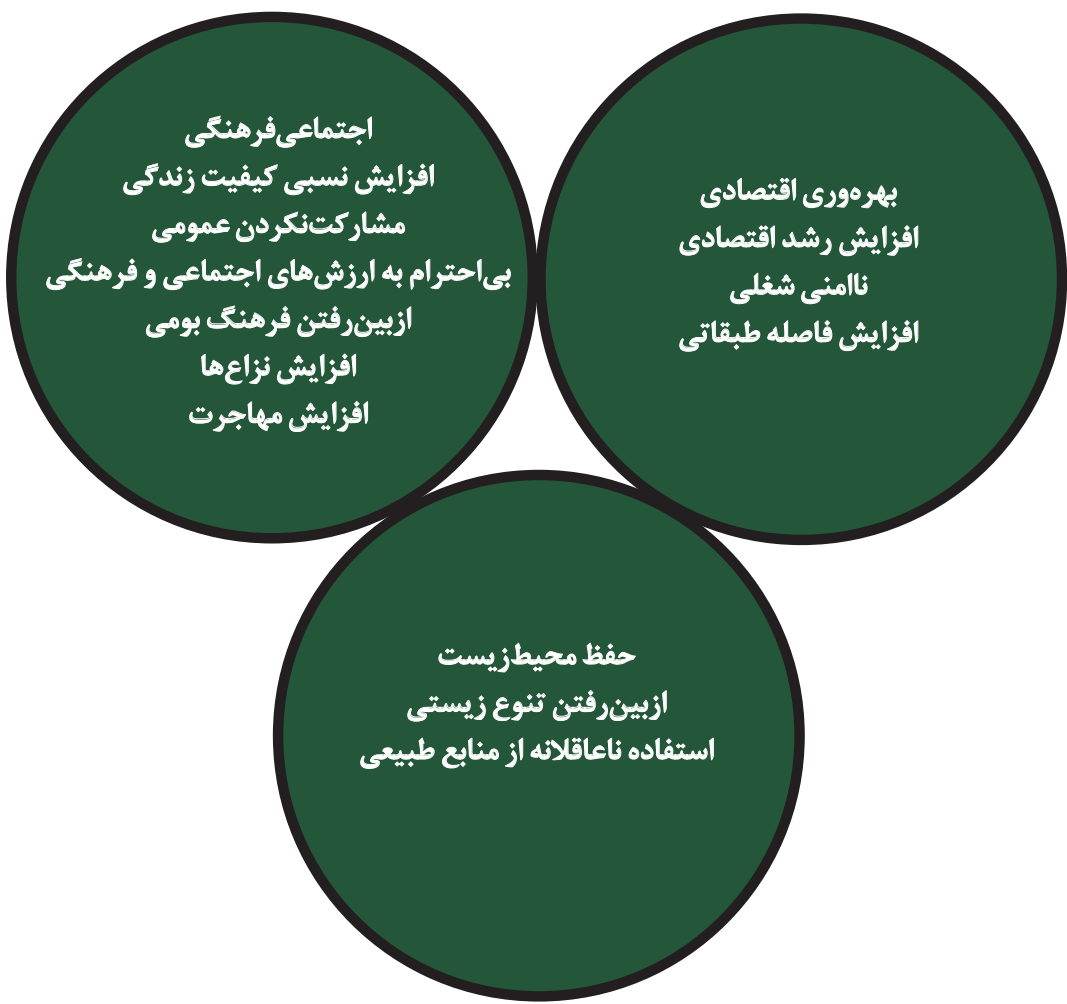

年

بهودنوان مثال بهبود نسبى وضعيت اقتصادى حاصل از رشد

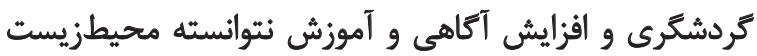

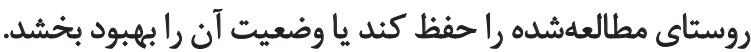
علاوهبراين ابعاد اقتصادى و اجتماعى نتوانسته

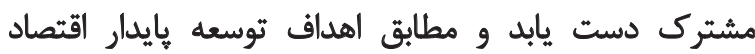
عدالتمحور رانهادينه كند (تصوير شماره بَ).

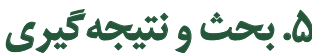

كردشكرى روستايى مي تواند به ايجاد فرصتهاى شغلى

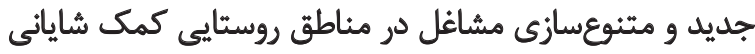

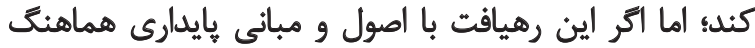

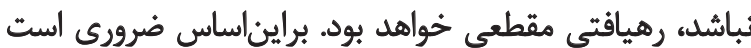

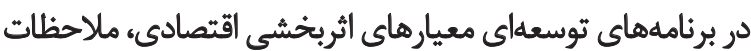

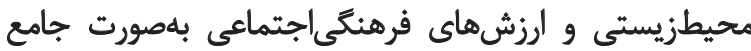

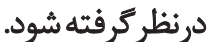

در بُعد اجتماعىفرهنكَى نتايج برؤوهشهاى شيلينَ و همكاران

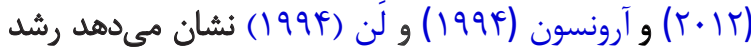

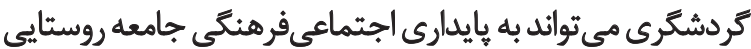

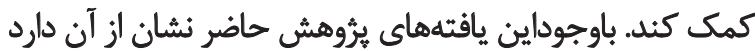

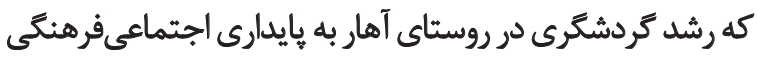
روستاى بررسى شده كمك نكرده است. يافته هاي نظرى و ميداني
تصوير "ّا. الكوى ابعاد توسعه بإيدار تردشكَىى در روستاى آهار. آلودقى هوا و كودبردارىهاى غيراصولى را ازجمله نترانىهاى جذّى خود عنوان كردند.

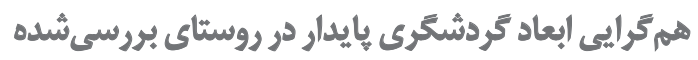
يافتههاى برثوهش نشان مي دهد در بُعد زيستمحيطى تخريب

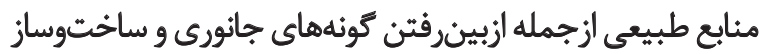

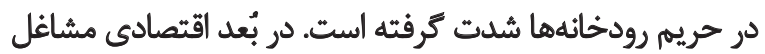

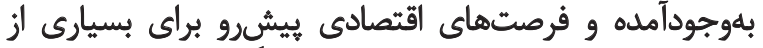

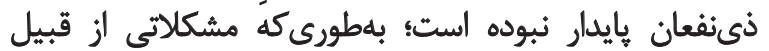

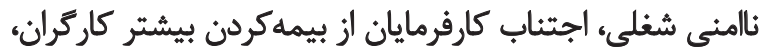

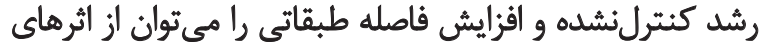

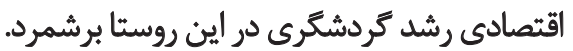

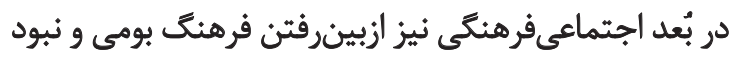

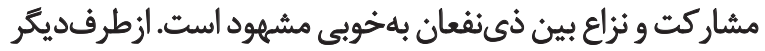

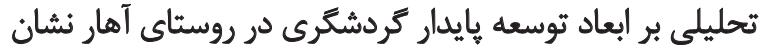

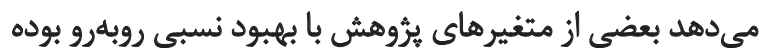

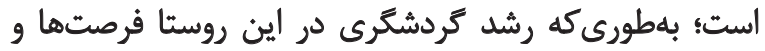

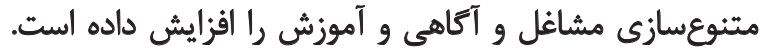

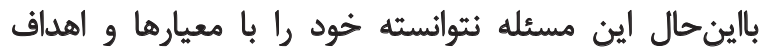

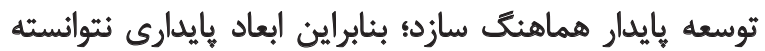
از يكديكر بشتيبانى كند و به كاركردهاى مشترك دست ينائ يابد. 
و ناأكاهى آنها از مؤلفههاى توسعه بِايدار باشد. ازسوى ديكّر نبود قوانين مدوّن و محكم نيز به اين مشكلات دائ دامن مىزند.

تحليل محتواى مصاحبههاي انجامشده از ذئنفعان نشان

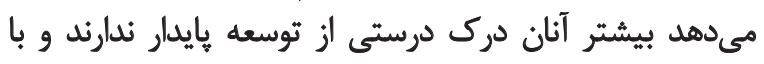

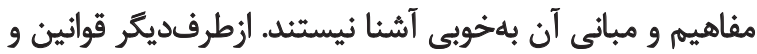

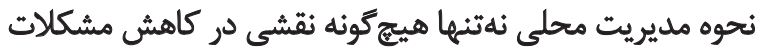

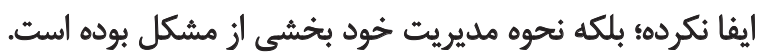

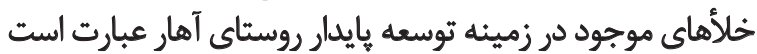

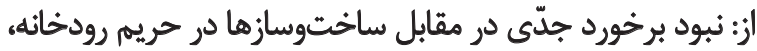

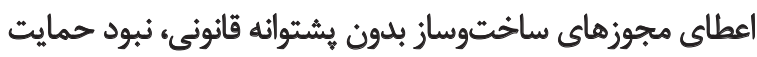

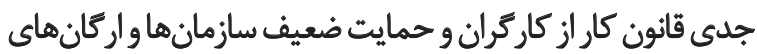
محيطزيستى در حفاظت از كونهانى كمياب كياهى و جانورى

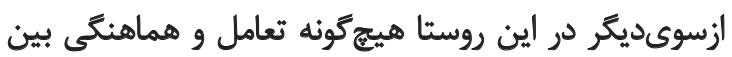

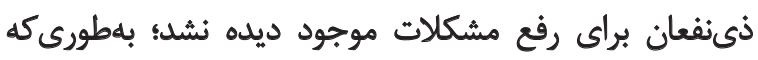

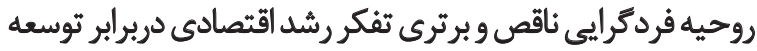

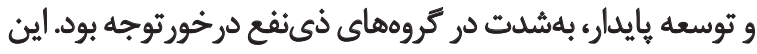

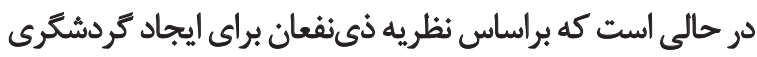

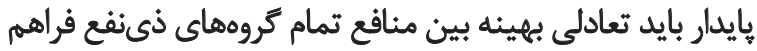

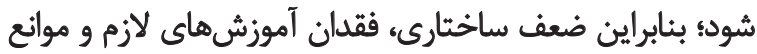

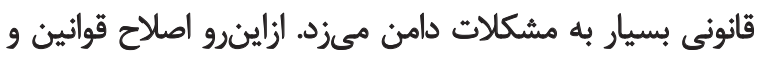

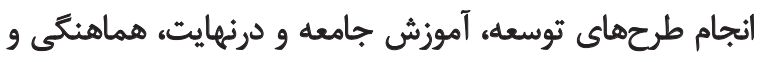

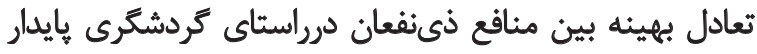
مى تواند به وضعيث لجام كسيخته در اين روستا كمك كند.
اين يُروهش حاكى از آن است كه هدف و نوع كردشكَّى مي تواند

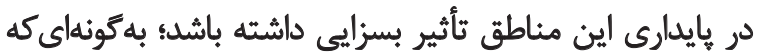

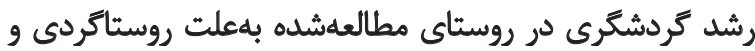

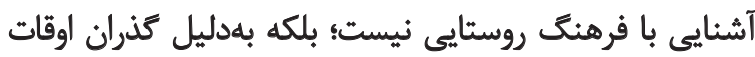

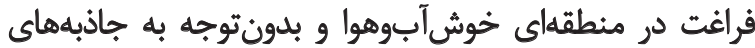
اجتماعى فرهنكى روستاست.

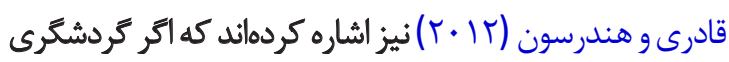

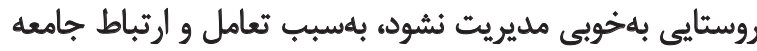

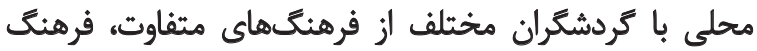

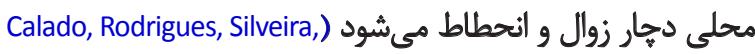
Sرد \&entinho, 2011; Ghaderi \& Henderson, 2012

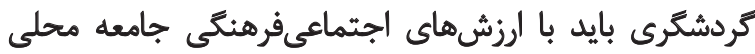

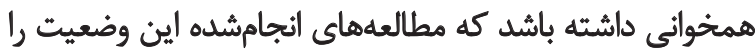

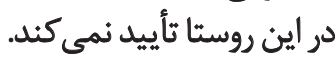

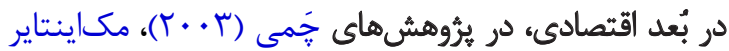

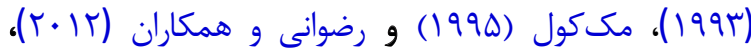

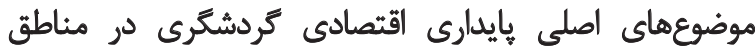

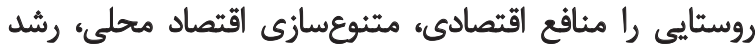

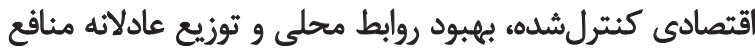

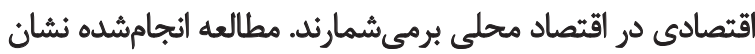

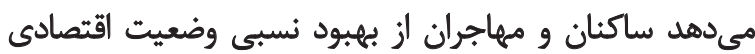

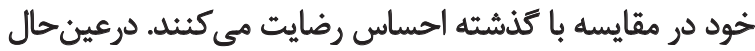

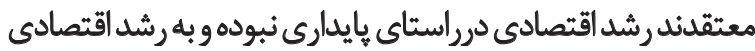

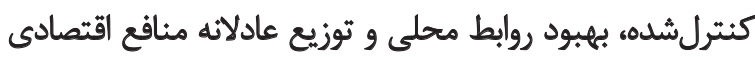

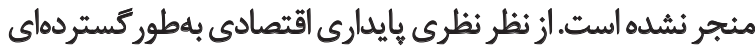

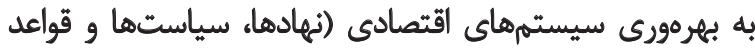

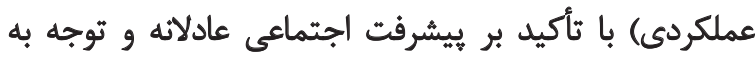

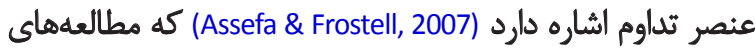
انجامشده اين وضعيت رادر اين روستا تأييد نمى كند.

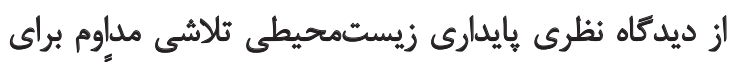

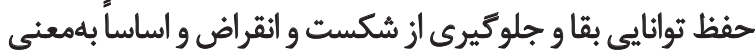

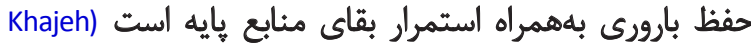

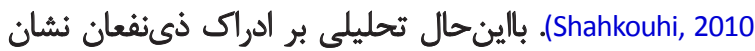

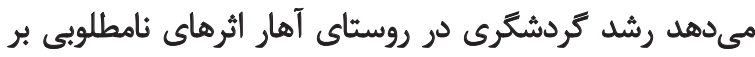

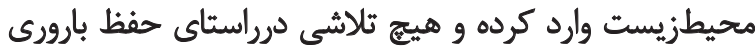

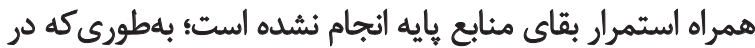

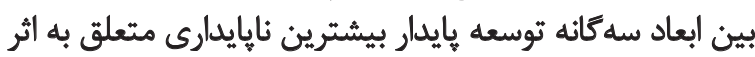

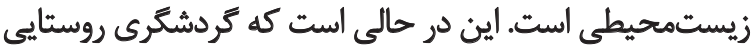

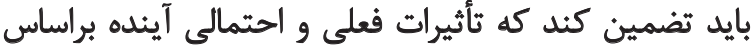

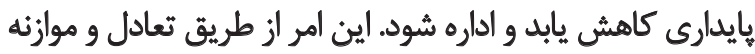

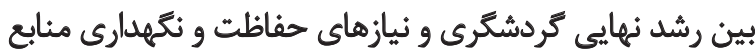

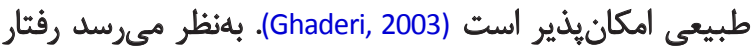

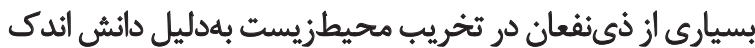




\section{References}

Abbas, M. Y., \& Bajunid, A. F. (2015). Asia Pacific International Conference on Environment-behaviour Studies. Procedia-Social and Behavioral Sciences, 168, 1-7.

Amir, A. F., Ghapar, A. A., Jamal, S. A., \& Ahmad, K. N. (2015). Sustainable tourism development: a study on community resilience for rural tourism in Malaysia. Procedia-Social and Behavioral Sciences, 168, 116-22.

Ap, J. (1992). Residents' perceptions on tourism impacts. Annals of tourism Research, 19(4), 665-90.

Aronsson, L. (1994). Sustainable tourism systems: the example of sustainable rural tourism in Sweden. Journal of Sustainable Tourism, 2(1-2), 77-92.

Assefa, G., \& Frostell, B. (2007). Social sustainability and social acceptance in technology assessment: a case study of energy technologies. Technology in Society, 29(1), 63-78.

Azimi Amoli, J. (2011). [Analysis of good governance in the stability of the countryside: the study villages in Mazandaran (Persian)] (PhD thesis). Tehran: Tarbiat Modares University.

Bălan , M., \& Burghelea, C. (2015). Rural Tourism and its Implication in the Development of the Fundata Village. Procedia-Social and Behavioral Sciences, 188, 276-81.

Bayat, N., \& Rezvani, M. (2013). [The analysis of role of rural tourism in macro program (with emphasis on the five-year national development plans) (Persian)]. Planning and Development of Tourism, 9, 11-30.

Bayat, N., Badri, S. A., Rezvani, M. R., \& Sabokbar, H. F. (2014). [Meta-analysis on rural tourism studies in Iran: a Q-methodology research (Persian)]. Research and Rural Planning, 7, 85-99.

Bryson, J. M. (2003). What to do when stakeholders matter: a guide to stakeholder identification and analysis techniques. Public Management Review, 6(1), 21-53.

Butler, R. W. (1991). Tourism, environment, and sustainable development. Environmental Conservation, 18(3), 201-09.

Byrd Jr, E. T. (2003). An analysis of variables that influence stakeholder participation and support for sustainable tourism development in rural North Carolina (Doctoral dissertation). Carolina: North Carolina State University.

Byrd, E. T. (2007). Stakeholders in sustainable tourism development and their roles: applying stakeholder theory to sustainable tourism development. Tourism Review, 62(2), 6-13.

Byrd, E. T., Bosley, H. E., \& Dronberger, M. G. (2009). Comparisons of stakeholder perceptions of tourism impacts in rural eastern North Carolina. Tourism Management, 30(5), 693-703.

Calado, L., Rodrigues, A., Silveira, P., \& Dentinho, T. (2011). Rural tourism associated with agriculture as an economic alternative for the farmers. European Journal of Tourism, Hospitality and Recreation, 2(1), 160 .

Chami, C. A. (2003). Sustainable tourism development: A comparison between Tanzania and Kenya (Unpoblished PhD dissertation). University of Alberta.

Ekinci, M. B. (2014). The Cittaslow philosophy in the context of sustainable tourism development; the case of Turkey. Tourism Management, 41, 178-89.
Falak, S., Chiun, L. M., \& Wee, A. Y. (2014). A repositioning strategy for rural tourism in Malaysia: community's perspective. Procedia Social and Behavioral Sciences, 144, 412-15.

Fons, M. V., Fierro, J. A., \& Patiño, M. G. (2011). Rural tourism: a sustainable alternative. Applied Energy, 88(2), 551-57.

Freeman, R. E. (1983). Strategic management: a stakeholder approach. Advances in Strategic Management, 1(1), 31-60.

Freeman, R. E. (2004). The stakeholder approach revisited. Zeitschrift für Wirtschafts-und Unternehmensethik, 5(3), 228-41.

Freeman, R. E. (2010). Strategic management: a stakeholder approach. Cambridge: Cambridge University Press.

Freeman, R. E., \& Phillips, R. A. (2002). Stakeholder theory: A libertarian defense. Business Ethics Quarterly, 12(3), 331-49.

Freeman, R. E., Harrison, J. S., \& Wicks, A. C. (2007). Managing for stakeholders: survival, reputation, and success. New Haven: Yale University Press.

Friedman, A. L., \& Miles, S. (2006). Stakeholders: theory and Practice: Theory and Practice. Oxford: Oxford University Press.

Fun, F. S., Chiun, L. M., Songan, P., \& Nair, V. (2014). The impact of local communities' involvement and relationship quality on sustainable rural tourism in rural area, Sarawak. The moderating impact of self-efficacy. Procedia-Social and Behavioral Sciences, 144, 60-65.

Ghaderi, E. (2003). [The role of rural tourism in sustainable rural development (Persian)] (Unpublished PhD thesis). Tarbiat Modarres University.

Ghaderi, Z., \& Henderson, J. C. (2012). Sustainable rural tourism in Iran: a perspective from Hawraman village. Tourism Management Perspectives, 2, 47-54.

Ghasemi, M., \& Hamzah, A. (2014). An investigation of the appropriateness of tourism development paradigms in rural areas from main tourism stakeholders' point of view. Procedia-Social and Behavioral Sciences, 144, 15-24.

Gunn, C. A., \& Var, T. (2002). Tourism planning: basics, concepts, cases. London: Psychology Press.

Hall, C. M., \& Lew, A. A. (2009). Understanding and managing tourism impacts: an integrated approach. London: Routledge Press.

Hall, D., Roberts, L., \& Mitchell, M. (2003). New directions in rural tourism. Aldershot, U.K.: Ashgate Publication.

Harrison, J. S., \& Freeman, R. E. (1999). Stakeholders, social responsibility, and performance: empirical evidence and theoretical perspectives. Academy of Management Journal, 42(5), 479-85.

Hwang, J., \& Lee, S. (2015). The effect of the rural tourism policy on non-farm income in South Korea. Tourism Management, 46, 501-13.

Iluiu-Varvara, D. A., Mârza, C. M., Sas-Boca, I. M., \& Ceclan, V. A. (2015). The assessment and reduction of carbon oxides emissions at electric arc furnaces-essential factors for sustainable development. Procedia Technology, 19, 402-09.

Jaafar, M., Rasoolimanesh, S. M., \& Lonik, K. A. T. (2015). Tourism growth and entrepreneurship: empirical analysis of development of rural highlands. Tourism Management Perspectives, 14, 17-24. 
Jamal, T. B., \& Getz, D. (1995). Collaboration theory and community tourism planning. Annals of Tourism Research, 22(1), 186-204.

Khaje Shahkouhi, A. (2010). [The analysis of the exploitative familial farming systems and rural production coopratives in the city of AQ Qala (Persian)] (PhD Thesis). Tehran: Tehran University.

Khavarian-Garmsir, A. R., \& Zare, S. M. (2015). SOAR framework as a new model for the strategic planning of sustainable tourism. Tourism Planning \& Development, 12(3), 321-32.

Kim, S., \& Jamal, T. (2015). The co-evolution of rural tourism and sustainable rural development in Hongdong, Korea: complexity, conflict and local response. Journal of Sustainable Tourism, 23(8-9), 1363-385.

Lafreniere, K. C., Deshpande, S., Bjornlund, H., \& Hunter, M. G. (2013). Extending stakeholder theory to promote resource management initiatives to key stakeholders: a case study of water transfers in Alberta, Canada. Journal of Environmental Management, 129, 81-91.

Lane, B. (1994). Sustainable rural tourism strategies: a tool for development and conservation. Journal of Sustainable Tourism, 2(1-2), 102-11.

Liu, A. (2006). Tourism in rural areas: Kedah, Malaysia. Tourism Management, 27(5), 878-89.

McCool, S. F. (1995). Linking tourism, the environment, and concepts of sustainability: setting the stage. In S. F. McCool \& A. E. Watson (Eds.), Linking tourism, the environment, and concepts of sustainability (General Technical Report INT-GTR-323) (pp.3-7). Ogden, U.T.: Intermountain Research Station.

McIntyre, G. (1993). Sustainable tourism development: guide for local planners. Madrid: World Tourism Organization.

Moshiri, S. R., Mahdavi, M., \& Jalali Kalej-Sar, Z. (2012). [Quality evalaution of tourism rural at development: Case study of Ahar) (Persian)]. Territory, 8(4), 1-26.

Phillips, R., Freeman, R. E., \& Wicks, A. C. (2003). What stakeholder theory is not. Business Ethics Quarterly, 13(4), 479-502.

Rezvani, M., Akbarian, R. S., Rokn, A. E. A., \& Badri, S. (2012). [Explanation on sustainability indicators for assessing the effects of tourism patterns in rural areas in around metropolises (case study: rural areas in the around of Tehran metropolis) (Persian)]. Human Geograohy Research, 81, 69-93.

Schilling, B. J., Sullivan, K. P., \& Komar, S. J. (2012). Examining the economic benefits of agritourism: the case of New Jersey. Journal of Agriculture, Food Systems and Community Development, 3(1), 199 214.

Schloegel, C. (2007). Sustainable Tourism: Sustaining Biodiversity? Journal of Sustainable Forestry, 25(3-4), 247-64.

Snieška, V., Barkauskienė, K., \& Barkauskas, V. (2014). The impact of economic factors on the development of rural tourism: Lithuanian case. Procedia-Social and Behavioral Sciences, 156, 280-85.

Su, B. (2011). Rural tourism in China. Tourism Management, 32(6), 1438-441.

Van der Duim, V. (2005). Tourismscapes: an actor-network perspective on sustainable tourism development (PhD thesis). Wageningen, D.C.: Wageningen University.
Weaver, D. B. (2006). Sustainable tourism: theory and practice. London: Routledge Press.

Wicks, A. C., Gilbert Jr, D. R., \& Freeman, R. E. (1994). A feminist reinterpretation of the stakeholder concept. Business Ethics Quarterly, 4(4), 475-97.

Yagüe Perales, R. M. (2002). Rural tourism in Spain. Annals of Tourism Research, 29(4), 1101-110.

Yuksel, F., Bramwell, B., \& Yuksel, A. (1999). Stakeholder interviews and tourism planning at Pamukkale, Turkey. Tourism Management, 20(3), 351-60.

Ziaei, M., Amin Bidokhti, A. A., \& Qorbani, F. (2015). [Assessment of the local community capacity for the sustainable development of tourism (Persian)]. Tourism Management Studies, 8(4), 59-88. 
